\title{
Persepsi Peternak dan Penyuluh LapanganTentang Faktor-Faktor Yang Berpengaruh Terhadap Keberhasilan Upsus Siwab di Kabupaten Kutai Timur \\ Nursida $^{1}$ dan Imam Sanusi ${ }^{2}$

\author{
1,2 Sekolah Tinggi Pertanian Kutai Timur, Jl. Sukarno Hatta no.1 Sangata, Kutai \\ Timur, Kalimantan Timur
} \\ 1 Email : nursida@stiperkutim.ac.id
}

\begin{abstract}
Upsus SIWAB (Upaya Khusus Sapi Indukan Wajib Bunting) is an effort to increase cattle population in the context of achieving food self-sufficiency through Artificial Insemination and Natural Marriage activities. The success of Upsus SIWAB is influenced by many factors that can be perceived by breeder and field extension. This study aimed to determine the perceptions of breeder, perceptions of field extension and the correlation between perceptions of breeder and field extension about the factors that influence the success of Upsus SIWAB in East Kutai District. This study had been done on 2019 in East Kutai District with the total respondent is 48 consisting of 40 breeder and 8 field extension. Data collection techniques are focus group discussion in four Sub-District. Data analysis by using descriptive and Rank Spearman. Each respondent will rank perceptions of all instruments that influence the success of Upsus SIWAB. The most influential instruments are given the smallest ranking (1), then sorted 2, 3, 4 to 17 which are considered the smallest influence. This study result had found that the ranking sequence that most influential in the success of Upsus SIWAB was based on breeder perceptions and extension agent is instrument number $6,3,5,4,2,7,14,1,11,10,8,13,15,9,16,12$, and 17. Rank Spearman result test is 0.769 , it means there is a strong correlation between breeder perceptions and extension agents about the factors that influence the success of the Upsus SIWAB in East Kutai District.
\end{abstract}

Keywords: Breeder, Extention Agent, Perception, Rank-Spearman Correlation, Upsus SIWAB

ABSTRAK
Upsus SIWAB (Upaya Khusus Sapi Indukan Wajib Bunting) adalah peningkatan populasi sapi dalam rangka pencapaian swasembada pangan melalui kegiatan Inseminasi Buatan dan Kawin Alam. Keberhasilan upsus SIWAB dipengaruhi oleh banyak faktor yang bisa dipersepsikan oleh peternak maupun penyuluh lapangan. Penelitian bertujuan untuk mengetahui persepsi peternak, persepsi penyuluh lapangan serta korelasi antara persepsi peternak dan penyuluh tentang faktor-faktor yang berpengaruh terhadap keberhasilan Upsus SIWAB di kabupaten kutai timur. Penelitian dilaksanakan pada tahun 2019 di Kabupaten Kutai Timur dengan jumlah responden sebanyak 48 yang terdiri dari 40 peternak dan 8 penyuluh lapangan. Teknik pengambilan data yang digunakan adalah Focus Group Discussion di empat kecamatan. Data dianalisis mengunakan deskriptif dan Rank Spearman. Hasil Penelitian menemukan bahwa urutan ranking yang paling berpengaruh dalam keberhasilan Upsus SIWAB berdasarkan persepsi peternak dan penyuluh lapangan adalah instrumen nomor $6,3,5,4,2,7,14,1,11,10,8,13,15,9,16,12$, dan 17. Hasil uji korelasi Rank Spearman adalah 0,769 berarti bahwa terdapat korelasi yang kuat antara persepsi peternak dan penyuluh lapangan tentang faktor-faktor yang berpengaruh terhadap keberhasilan Upsus SIWAB di Kabupaten Kutai Timur.

Kata Kunci : Korelasi Rank Spearman, Persepsi, Peternak, Penyuluh Lapang, Upsus SIWAB

Pendahuluan

Kualitas sumberdaya manusia dipengaruhi oleh bahan pangan yang dikonsumsi baik dari jumlah maupun kualitasnya. Industri peternakan memegang peranan penting 
ISSN 2354-7251 (print)

sebagai penyedia bahan pangan yang memiliki nilai gizi yang berkualitas, sebagai sumber protein dan energi seperti daging, telur, dan susu. Permintaan terhadap komoditas tersebut terus meningkat seiring pertambahan penduduk, peningkatan pendapatan, perbaikan tingkat pendidikan, dan tingkat kesadaran masyarakat tentang gizi seimbang.

Sapi potong merupakan ternak ruminansia yang memegang peranan penting dalam penyediaan daging nasional, namun daging sapi lokal rata-rata baru memenuhi $65,24 \%$ kebutuhan total nasional sehingga kekurangannya masih dipenuhi dari impor, baik berupa sapi bakalan maupun daging beku (Iswoyo dan Widyaningrum, 2008). Dalam rangka pencapaian peningkatan populasi ternak ruminansia khususnya sapi di dalam negeri, maka

Kementerian Pertanian RI melalui Peraturan Menteri Pertanian Nomor 48/Permentan/PK.210/10/2016 tentang Upaya Khusus Percepatan Peningkatan Populasi Sapi dan Kerbau Bunting yang telah dicanangkan dalam bentuk Upsus Siwab. Upsus siwab merupakan salah satu kegiatan upaya pembangunan peternakan untuk peningkatan populasi dalam rangka pencapaian swasembada pangan serta peningkatan kesejahteraan masyarakat. Terdapat dua program utama upsus siwab yaitu peningkatan populasi melalui Inseminasi Buatan (IB) dan Intensifikasi Kawin Alam (Inka). Sebanyak 4 juta ekor sapi disiapkan sebagai akseptor IB, dari jumlah tersebut ditargetkan 3 juta kehamilan baru. Namun, hingga awal September 2017, berdasarkan data kumulatif secara nasional, sapi yang sudah diberikan IB sebanyak 2.443 .658 ekor dengan angka kebuntingan baru mencapai 829.555 ekor dan jumlah kelahiran tercatat sebanyak 518.620 ekor (Prasetyo, 2017).

Dinas pertanian Kutai timur adalah instansi pemerintah di Provinsi Kalimantan timur yang mengakselerasi instruksi pemerintah tentang program Upsus Siwab. Program ini telah dijalankan sejak tahun 2017 oleh bagian kesehatan hewan dengan target pelaksanaan IB sebanyak 7.000 ekor sapi betina produktif, namun dari target tersebut hanya sekitar 950 ekor saja yang tercapai, sehingga pada tahun 2018 target IB turun menjadi 700 ekor. Data tentang kelahiran pedet hasil IB sejak program Upsus Siwab dijalankan belum diketahui secara pasti, sehingga populasi sapi di Kabupaten Kutai Timur dari tahun 2017-2018 belum mengalami peningkatan yang signifikan.

Peranan kelembagaan mulai dari tingkat peternak dalam memberikan informasi tentang induk betina yang sedang birahi kepada tim inseminator sangat perlu untuk mengetahui waktu yang paling tepat dilaksanakannya IB terhadap sapi, serta kompetensi penyuluh dan dukungan dari pemerintah sangat berperan dalam pencapaian target upsus siwab tersebut. Peternak, penyuluh lapangan maupun dinas tentu memiliki kepentingan dari kegiatan Upsus SIWAB, baik untuk meningkatkan pendapatan maupun mensukseskan program pemerintah. Beberapa faktor yang diduga berpengaruh terhadap tingkat keberhasilan program upsus siwab, diantaranya minimnya pengetahuan peternak tentang 
tanda sapi yang sedang birahi, keterbatasan petugas inseminator, dan jarak yang terlalu jauh. Perpespsi tentang faktor yang berpengaruh tersebut didasarsi oleh tingkat kepentingan dari pelaksana program. Perbedaan kepentingan akan menimbulkan perbedaan persepsi diantara pelaksanaan program tersebut.

Tujuan penelitian adalah untuk mengetahui persepsi peternak dan petugas penyuluh lapang (PPL) tentang faktor-faktor yang berpengaruh terhadap keberhasilan Upsus Siwab di Kabupaten Kutai Timur, dan mengetahui korelasi antara persepsi peternak dan persepsi penyuluh lapangan tentang faktor faktor yang berpengaruh terhadap keberhasilan Upsus SIWAB di Kabupaten Kutai Timur.

\section{Metode Penelitian}

\section{Lokasi Penelitian}

Penelitian dilaksanakan pada tahun 2019 di lima kecamatan yang ada di Kabupaten Tutai timur, yakni Kecamatan Sangkulirang, Kecamatan Rantau Pulung, Kecamatan Bengalon, Kecamatan Kaliorang, dan Kecamatan Sangata Selatan.

\section{Populasi dan Sampel}

Populasi dalam penelitian adalah semua aspek yang terlibat dalam kegiatan Upsus SIWAB di Kabupaten Kutai Timur. Sampel dalam penelitian di kelompokkan menjadi dua, yaitu 1) petani yang memiliki ternak sapi potong, dan 2) petugas PPL dinas pertanian Kabupaten Kutai Timur. Teknik sampling dilakukan dengan cara multistage samlping, yaitu pengambilan sampel secara bertingkat (Nasution, 2003). Metode pertama yaitu snowball sampling, yaitu teknik penentuan sampel yang mula-mula jumlahnya kecil kemudian membesar (Sugiyono, 2015). Sumber informasi yang pertama dari kepala bagian kesehatan hewan untuk mengetahui PPL di setiap kecamatan, kemudian dari PPL diketahui peternak yang telah melalukan IB. Teknik sampling yang kedua adalah kuota sampling dimana jumlah sampel setiap kecamatan sebanyak 12 yang terdiri dari 10 peternak dan 2 penyuluh lapangan sehingga jumlah sampel yang digunakan dalam penelitian sebanyak 48 responden.

\section{Jenis, Instrumen dan Teknik Pengambilan Data}

Jenis data yang digunakan dalam penelitian adalah data primer dan data sekunder. Data primer diperoleh melalui wawancara dengan peternak dan data sekunder diperoleh dari berbagai literatur yang mendukung penelitian. Pengambilan data dilakukan dengan menggunakan kuisioner yang berisi identitas responden dan 17 instrumen yang diteliti. Setiap responden memberikan ranking persepsinya terhadap semua intrumen yang berpengaruh terhadap keberhasilan Upsus SIWAB. Instrumen yang paling berpengaruh diberikan ranking terkecil (1), kemudian di urut 2, 3, 4 sampai ranking 17 yang dianggap pengaruhnya paling kecil, seperti yang terdapat pada Tabel 1. 
ISSN 2354-7251 (print)

Tabel 1. Urutan Rangking dan Instrumen Yang Berpengaruh Terhadap Keberhasilan Upsus

SIWAB Di Kabupaten Kutai Timur, 2019

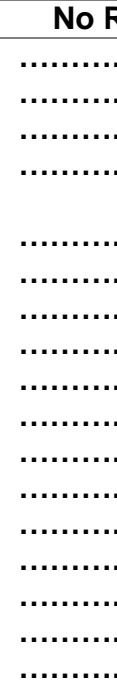

1. Tingkat Pendidikan peternak Instrumen

2. Tingkat Pendidikan PPL

3. Pengenalan tanda-tanda birahinsapi indukan oleh peternak

4. Pengetahuan PPL tentang waktu yang paling tepat pelaksanaan IB

5. Kualitas semen

6. Kondisi kesehatan sapi indukan

7. Ketersediaan pakan

8. Wilayah kerja PPL

9. Pola pemeliharaan sapi (perkandangan)

10. Jarak poskeswan dengan lokasi sapi indukan

11. Jumlah tenaga san waktu PPL dalam melaksanakan IB

12. Fasilitas internet

13. Dana operasional dari pemerintah

14. Kesadaran peternak dalam melaksanakan IB

15. Pemeriksaan kebutingan oleh PPL

16. Identitas peternak

17. Kartu kontrol ternak

\section{Analsisi diskriptif}

Bentuk data yang digunakan adalah data ordinal (bertingkat), setiap instrumen yang diteliti akan di berikan peringkat dari instrumen yang memiliki pengaruh paling besar menurut persepsi responden di beri peringkat satu (1) sampai yang pengaruhnya sangat kecil di beri peringkat 17 , semakin kecil peringkatnya, maka intrumen tersebut dinilai paling besar pengaruhnya.

\section{Analisis Korelasi}

Analisis digunakan untuk mengetahui korelasi antara peternak dan PPL dalam mempersepsikan faktor yang berpengaruh, maka digunakan Rank Spearman. Korelasi Rank Spearman digunakan untuk mencari hubungan atau untuk menguji sifnigikasi hipotesis asosiatif bila masing-masing variabel yang dihubungkan berbentuk ordinal dan sumber data antar variabel tidak harus sama (Sugiyono, 2015) dengan Rumus :

$$
\mathrm{Rs}=1-\frac{6 \sum_{i-1}^{n} d i^{2}}{n\left(n^{2}-1\right)}
$$

Kriteria pengujian hipotesis : $\mathrm{H}_{0}$ diterima bila $\rho_{\text {hitung }}$ lebih kecil dari $\rho_{\text {tabel }}$ dengan taraf kesalahan $5 \%$

\section{Hasil dan Pembahasan}

Persepsi Peternak dan Penyuluh tentang faktor-faktor yang berpengaruh terhadap keberhasilan Upsus SIWAB di Kutai Timur

Berdasarkan data penelitian, diketahui bahwa ranking persepsi peternak dan penyuluh tetang faktor-faktor yang berpengaruh terhadap Upsus SIWAB berbeda seperti yang terdapat pada Tabel 2. 
Tabel 2. Ranking persepsi peternak dan penyuluh tentang faktor-faktor yang berpengaruh terhadap keberhasilan Upsus SIWAB di Kutai Timur

\begin{tabular}{|c|c|c|c|c|c|}
\hline \multirow[t]{2}{*}{ No } & \multirow[t]{2}{*}{ Instrumen } & \multicolumn{2}{|c|}{ Peternak } & \multicolumn{2}{|c|}{ Penyuluh } \\
\hline & & Nilai Persepsi & $\begin{array}{c}\text { Rank } \\
\text { Persepsi }\end{array}$ & $\begin{array}{c}\text { Nilai } \\
\text { persepsi }\end{array}$ & $\begin{array}{l}\text { Ranking } \\
\text { Persepsi }\end{array}$ \\
\hline 1. & Tingkat Pendidikan peternak & 334 & 8 & 67 & 8 \\
\hline 2. & Tingkat pendidikan PPL & 302 & 6 & 49 & 5 \\
\hline 3. & $\begin{array}{l}\text { Pengetahuan tanda-tanda birahi/ estrus) sapi } \\
\text { indukan oleh peternak }\end{array}$ & 230 & 4 & 34 & 1 \\
\hline 4. & $\begin{array}{l}\text { Pengetahuan PPL tentang waktu paling tepat } \\
\text { pelaksanaan IB }\end{array}$ & 299 & 5 & 47 & 4 \\
\hline 5. & Kualitas semen & 199 & 3 & 46 & 2,5 \\
\hline 6. & Kondisi sapi indukan & 183 & 2 & 46 & 2,5 \\
\hline 7. & Ketersediaan pakan & 156 & 1 & 79 & 12 \\
\hline 8. & Wilayah kerja PPL & 361 & 10 & 70 & 9 \\
\hline 9. & Pola pemeliharaan sapi (perkandangan) & 307 & 7 & 75 & 10,5 \\
\hline 10. & Jarak puskeswan dengan lokasi sapi indukan & 445 & 14 & 93 & 13 \\
\hline 11. & $\begin{array}{l}\text { Jumlah tenaga dan waktu PPL dalam } \\
\text { melakukan IB terhadap sapi indukan }\end{array}$ & 386 & 11 & 66 & 7 \\
\hline 12. & Fasilitas internet & 600 & 17 & 102 & 15 \\
\hline 13. & Dana operasional dari pemerintah & 394 & 13 & 75 & 10,5 \\
\hline 14. & Kesadaran peternak dalam melakukan IB & 355 & 9 & 59 & 6 \\
\hline 15. & Pemeriksaaan kebuntingan oleh PPL & 387 & 12 & 95 & 14 \\
\hline 16. & Identitas peternak & 579 & 15 & 107 & 15 \\
\hline 17 & Kartu kontrol ternak & 594 & 16 & 119 & 17 \\
\hline
\end{tabular}

\section{Tingkat pendidikan peternak}

Tingkat pendidikan peternak merupakan tahapan pendidikan yang telah dilalui oleh peternak dimana akan berpengaruh pada pola pikir dan sikap peternak dalam mendukung program pemerintah untuk meningkatkan populasi ternak sapi melalui upaya khusus sapi indukan wajib bunting. Hasil penelitian pada Tabel 2, bahwa peternak dan penyuluh lapangan memiliki persepsi yang sama tentang tingkat pendidikan peternak berada pada urutan ke- 8 yang mempengaruhi keberhasilan program Upsus SIWAB di kabupaten Kutai Timur. Kenyataan dilapangan bahwa $70 \%$ dari responden dengan tingkat pendidikan rendah yakni SD dan SMP sehingga berpengaruh pada pola pemeliharaan serta skala usaha yang dimiliki peternak. Kutsiyah (2012) menyatakan bahwa pendidikan yang rendah biasanya usaha peternakannya selalu kecil, bersifat sederhana dan tradisional

\section{Tingkat pendidikan PPL}

Petugas Penyuluh Lapangan (PPL) memiliki peranan yang sangat penting yakni sebagai fasilitator dalam kegiatan penyuluhan. Penyuluh yang bertugas dalam pelaksanaan Upsus SIWAB harus memiliki pengetahuan dan keterampilan terutama dalam melaksanan IB. Pengetahuan dasar IB diperoleh saat mengikuti pendidikan formal di bidang peternakan baik ditingkat kejuruan maupun di pendidikan tinggi, namun penerapan IB di lapangan tidak mudah dilakukan sehingga petugas penyuluh lapang perlu mengikuti pendidikan non formal berupa pelatihan khusus untuk mendapatkan sertifikat dan izin dalam melaksanakan suntik IB. Anwas (2013) menyatakan bahwa kompleksitas pekerjaan penyuluhan pertanian tidak cukup terpenuhi oleh kemampuan yang dimiliki dari hasil pendidikan formal saja, pengetahuan dan wawasan mungkin ada peningkatan ketika 
dengan pendidikan formal, tetapi yang lebih terasa untuk melaksanakan tugas penyuluhan adalah pengalaman yang diperoleh di lapangan, terutama dalam melakukan ujicoba.

Pengetahuan tanda-tanda birahi sapi indukan oleh peternak

Persepsi PPL bahwa deteksi birahi sapi oleh peternak merupakan acuan petugas dalam menentukan waktu yang paling tepat untuk melaksanakan IB pada sapi sementara bagi peternak hal tersebut sudah bisa dimanipulasi dengan penyuntikan hormon oleh petugas penyuluh. Kendala di lapangan bahwa tidak semua peternak mampu mendeteksi birahi dengan baik dan pola pemeliharaan ternak dilakukan secara semi intensif bahkan ekstensif sehingga pengamatan birahi terutama pada sapi yang dipelihara secara ekstensif tidak dilakukan dengan baik oleh peternak. Baba et al. (2015) menyatakan bahwa pemahaman peternak tentang tanda-tanda berahi berada pada level sedang dimana peternak hanya mengetahui tanda berupa ternak yang gelisah dan vulva yang berwarna merah sebagai tanda sapi berahi.

Pengetahuan PPL tentang waktu paling tepat pelaksanaan IB

Instrumen ini dipersepsikan pada urutan ke-5 oleh peternak dan ke-4 oleh PPL sebagai faktor yang mentukan keberhasilan Upsus SIWAB. Petugas akan mengelolah informasi dari peternak mengenai waktu birahinya sapi kemudian menentukan waktu yang paling tepat untuk melaksanakan IB. Annashru, et al (2017) menyatakan bahwa perbedaan waktu pelaksanaan IB pada sapi berpengaruh terhadap keberhasilan kebuntingan, dimana tingkat kebuntingan sapi setelah dilakukan IB sebesar $70 \%$ pada interval waktu 0-4 jam setelah terdapat tanda-tanda birahi dibandingkan dengan IB yang dilakukan dengan interval 8-12 jam yang hanya $37,14 \%$.

Kualitas semen

IB adalah teknik memasukkan spermatozoa yang telah dicairkan dan diproses terlebih dahulu ke dalam saluran reproduksi ternak betina dengan menggunakan metode dan alat khusus. Kulitas semen beku sangat menentukan tingkat keberhasihan IB pada sapi betina sehingga faktor-faktor yang dapat mempengaruhi kualitas semen harus tetap diperhatikan agar fertilitasnya tetap baik. Pratiwi, et al. (2014) menyatakan terdapat banyak faktor yang dapat menurunkan kualitas semen mulai dari proses pengolahan terutama pada tahap pembekuan, penyimpanan dalam kontainer, dan distribusi semen beku itu sendiri. Menurut peternak Kualitas semen merupakan faktor ke-3 dalam keberhasilan UPSUS SIWAB sementara menurut PPL faktor ini pada urutan ke-5. Semen yang berkualitas telah memenuhi standar dan telah diuji baik secara makroskopis maupun secara mikroskopis. Fatah et al. (2018) menyatakan bahwa kualitas semen beku sapi unggul berpengaruh terhadap tingkat kebuntingan setelah inseminasi pada induk aseptor. 
Kondisi sapi indukan

Persepsi peternak dan PPL tentang Kondisi sapi indukan dipersepsikan sebagai faktor nomor 2 dan 2,5 yang berpengaruh dalam keberhasilan Upsus SIWAB. Sapi indukan merupakan sapi betina produktif yang digunakan untuk IB dalam menunjang program Upsus SIWAB. Kondisi sapi indukan yang dimaksud dalam penelitian adalah kondisi fisik yang meliputi bentuk tubuh, warna bulu, serta bobot badan dan kondisi psikis yakni kesiapan sapi induk dalam menerima calon anak. Kondisi dilapangan bahwa sebagian besar peternak memelihara dan memiliki induk sapi bali karena sapi tersebut mudah beradaptasi dengan lingkungan dan kemampuan reproduksi yang baik dibanding sapi-sapi lokal lainnya (Abidin, 2002), sementara beberapa kasus IB menggunakan semen beku dari jenis sapi yang lain dengan tujuan agar performance pedet lebih baik. Pedet hasil IB dengan menggunakan semen bos taurus seperti simmental dan limousin maupun bos indicus seperti brahman cross memiliki performance yang berbeda dengan pedet hasil kawin alam (Baba et al, 2015), sehingga berakibat pada ketidakmampuan induk saat akan melahirkan karena pedetnya besar.

\section{Ketersediaan pakan}

Ketersediaan pakan sangat penting untuk keberlangsungan usaha peternakan dan program-program pengembangan serta peningkatan populasi ternak di Indonesia. Instrumen ketersediaan pakan di persepsikan oleh peternak sebagai faktor ke-1 sementara PPL sebagai faktor ke-12 sebagai faktor yang berpengaruh terhadap keberhasilan Upsus SIWAB. Kondisi di lokasi penelitian bahwa sebagian besar lahan petani digunakan sebagai kebun kelapa sawit, kebun karet, ladang dan sawah sehingga ketersediaan pakan hijauan yang bermutu sangat kurang. Pakan hijauan merupakan sumber energi bagi ternak sapi. Pemberian pakan yang berkualitas menjelang perkawinan dapat meningkatkan kesuburan. Rendahnya angka konsepsi merupakan petunjuk kekurangan energi (Feradis, 2010).

\section{Wilayah kerja PPL}

Wilayah kerja PPL dipersepsikan sebagai faktor ke-10 oleh peternak dan faktor ke9 oleh PPL. Wilayah kerja PPL merupakan daerah yang menjadi kekuasaan petugas penyuluh dalam melaksanakan tugasnya. Jumlah pusat kesehatan hewan (puskeswan) yang ada di Kutai Timur sebanyak 5 (lima) yang melayani 18 Kecamatan dan setiap puskeswan hanya terdapat dua petugas IB sehingga wilayahnya kerjanya cukup luas karena setiap puskeswan bisa melayani lebih dari 2 kecamatan. Akses wilayah kerja PPL juga kurang bagus di mana jalanan ke lokasi kandang ternak sebagian besar kondisinya masih rusak yang diduga akan mempengaruhi kesehatan dan kinerja PPL (Haryati, 2008), kondisi kesehatan PPL yang kurang baik dikarenakan wilayah kerja yang terlalu luas dan usia yang sudah tua (di atas 40 tahun)

\section{Pola pemeliharaan sapi}


Pola pemeliharaan sapi adalah tindakan yang dipilih peternak dalam memelihara ternaknya. Pola pemeliharaan ternak yaitu ekstensif, semi intensif dan intensif. Penerapan metode pemeliharan oleh peternak dengan mempertimbangkan waktu mengurus dan ketersediaan pakan akan menentukan kualitas ternak tersebut. Pola pemeliharaan dipersepsikan peternak pada urutan ke-7 dan PPL pada urutan 10,5. Peternak sapi di Kabupaten Kutai Timur pada umumnya menggunakan sistem semi intesif yaitu sapi digembalakan pada pagi hari kemudian sore dimasukkan ke kandang yang telah disiapkan pakan berupa hijauan segar. Satrio (2018) menyebutkan bahwa cara yang paling tepat dalam peternakan sapi adalah dengan teknik semi-intensif karena ada keseimbangan antara nutrisi yang kita atur melalui pemberian di dalam kandang dengan nutrisi yang dibutuhkan oleh sapi dari alam.

Jarak poskeswan dengan lokasi sapi indukan

Persepsi peternak dan PPL bahwa jarak poskeswan dengan lokasi sapi indukan berpengaruh pada urutan ke-14 dan ke-13 dalam menentukan keberhasilan Upsus SIWAB. Puskeswan di wilayah penelitian umumnya berada di kota kecamatan, karena fasilitas yang diperlukan terkait dengan pelaksanaan IB seperti ketersediaan listrik untuk penyimpanan semen beku terpusat di kota. Sementara sapi indukan berada di kandang yang pada umumnya berjarak 2 kilometer dengan waktu tempuh bisa lebih dari 5 menit, jarak ini juga akan mempengaruhi ketepatan waktu pelaksanaan IB. Toelihere (1993) menyebutkan bahwa thawing semen harus segera diinseminasikan dalam waktu yang tidak lebih dari 5 menit.

Jumlah tenaga dan waktu PPL dalam melakukan IB terhadap sapi indukan

Instrumen jumlah tenaga dan waktu PPL melakukan IB dipersepsikan pada urutan ke-11 oleh peternak dan urutan ke-7 oleh PPL sebagai faktor yang berpengaruh terhadap keberhasilan Upsus SIWAB. PPL di Kutai Timur yang memiliki keahlian dalam melaksanakan IB jumlahnya terbatas yakni di setiap puskeswan hanya ada 2 dan wilayah kerjanya cukup luas sehingga saat peternak memberikan laporan terkait dengan keberadaan sapi birahi dalam waktu yang bersamaan, maka pelaksanaan IB tidak dilakukan pada waktu yang tidak tepat. Pelaksanaan IB oleh inseminator di Kutai Timur dilakukan jika ada dari peternak bahwa sapi mereka sedang birahi. Peternak sudah mengetahui tanda-tanda sapi berahi seperti gelisah dan vulva berlendir, namun mereka belum mengetahui waktu yang tepat untuk melaksanakan IB sehingga terkadang peternak memberikan informasi yang keliru kepada Inseminator (Baba et. al., 2015). Semen beku yang sudah dithawing tidak bisa disimpan lagi sehingga pelaksanaan IB tetap dilakukan sesuai dengan waktu kunjungan PPL meskipun waktu pelaksanaannya tidak tepat.

Fasilitas internet 
Jaringan internet dianggap berpengaruh dalam menentukan keberhasilan program Upsus siwab. Faktor fasilitas internet dipersepsikan oleh peternak pada urutan ke-17 oleh peternak dan ke-15 oleh PPL. Penyuluh lapangan menganggap bahwa ketersediaan jaringan internet sangat membantu dalam pelaporan kegiatan Upsus SIWAB. Sundari dan Sionita (2017) bahwa petugas inseminator, PKB dan ATR melaporkan kegiatan secara real time melalui sms gateway ke stakeholder terutama laporan jumlah sapi yang telah IB, jumlah sapi yang bunting serta kelahiran pedet hasil IB dan tentu saja dengan menggunakan aplikasi yang membutuhkan jaringan internet yaitu Sistem Informasi Kesehatan Hewan Nasional Terintegrasi (ISIKHNAS). Keberadaan jaringan internet bagi peternak dianggap kurang berpengaruh bagi usaha mereka, namun keberadaan jaringan internet memungkinkan peternak lebih cepat dalam memperoleh informasi yang akan digunakan untuk mengambil keputusan. Van den Ban dan Hawkins (1999) menyebutkan bahwa pengenalan dan pemanfaatan tekonologi informasi bagi petani masih kurang sehingga efeknya terhadap peningkatan pengelolaan usaha tani masih kurang, karena petani mengalami kesulitan dalam menggunakan ternologi tersebut dan teknologi informasi belum berhasil digunakan dalam bidang penyuluhan.

\section{Dana operasional dari pemerintah}

Dana operasional dari pemerintah dipersepsikan sebagai faktor urutan ke-13 oleh peternak dan urutan ke-10,5 oleh PPL. Kegiatan Upsus siwab meliputi program Identifikasi, program IB, dan program Pemeriksaan Kebuntingan (PKB). Kegiatan-kegiatan tersebut dapat efektif jika ditunjang dengan ketersediaan dana operasinal dari pemerintah. Aggaran Operasional yang diperoleh oleh petugas inseminator setiap melaksanakan IB bersumber dari APBN karena pelaksanaan IB dalam kegiatan Upsus SIWAB tidak membebankan biaya kepada pemilik ternak yang meliputi biaya operasional pelayanan IB dan biaya pemeriksaan kebuntingan dianggarkan untuk setiap pelayanan, biaya pelaporan kelahiran dan honor data recorder yan diberikan setiap bulan kepada petugas yang telah ditunjuk oleh masing-masing kabupaten.

\section{Kesadaran peternak dalam melaksanakan IB}

Metode IB sangat mendukung keberhasilan Upsus SIWAB karena dapat mengatur jarak kelahiran, menghemat biaya pemeliharan pejantan serta mencegah penularan penyakit. Keberhasilan IB sangat dipengaruhi oleh kesadaran peternak dan inseminator merupakan ujung tombak terlaksananya IB. Instrumen kesadaran peternak dalam melaksanakan IB dipersepsikan oleh peternak pada urutan ke-9 dan urutan ke-6 oleh PPL. PPL menganggap bahwa pelaksanaan IB sangat tergantung pada kesadaran dan kemauan peternak untuk melaksanakan IB. Informasi yang diperoleh dari PPL bahwa masih ada peternak yang belum mau dan bahkan membawa sapinya pulang ketika mereka tahu 
bahwa akan dilakukan suntik IB. Trauma peternak baik yang pernah melaksanakan IB maupun pengalaman dari orang lain mengakibatkan peternak tidak mau melaksanakan IB. Pemeriksaan kebuntingan oleh PPL

Pemeriksaan kebuntingan perlu dilakukan setelah pelaksanaan IB pada sapi betina baik dengan memperhatikan tingkah laku ternak. Hastuti (2008) menyebutkan bahwa tanda-tanda sapi potong yang bunting adalah peningkatan nafsu makan, tidak menunjukkan gejala berahi lagi dan perilaku menjadi lebih tenang. Pemeriksaan kebuntingan terlebih dahulu dilakukan oleh peternak dengan mengamati timbulnya birahi kembali dalam waktu 21 hari setelah IB. Kebuntingan pada sapi secara pasti dapat diketahui dengan memeriksa secara teliti terhadap sapi yang telah di IB oleh petugas inseminator atau petugas PKB setiap $50 \pm 60$ hari sesudah inseminasi dengan cara palpasi rektal.

Identitas peternak

Identitas peternak yang dimaksud dalam penelitian adalah tanda pengenal yang meliputi nama, alamat dan nomor handphone untuk memudahkan PPL dalam berkomunikasi dan memantau pelaksanaan Upsus SIWAB. Identitas peternak dipersepsikan oleh peternak dan penyuluh pada urutan ke-15 sebagai faktor yang mempengaruhi keberhasilan Upsus SIWAB di Kutai Timur. Kondisi di wilayah penelitian bahwa yang sering berkonumikasi dengan PPL adalah ketua kelompok tani. Rangkuti (2009) menyebutkan bahwa peran ketua kelompok tani mendominasi struktur jaringan komunikasi petani dalam proses adopsi inovasi.

Kartu kontrol ternak

Kartu kontrol ternak biasanya digunakan dalam pelayanan kesehatan dan pengendalian penyakit ternak. Keberadaan kartu kontrol sangat penting dalam pelaksanaan IB karena informasi tentang jumlah, silsilah dan reproduksi sapi betina. Anggraeni dan Mariana (2016) menyatakan bahwa pencatatan yang tertib dan teratur dapat membantu dalam menilai berhasil tidaknya usaha peternakan. Pencatatan yang baik oleh peternak akan mudah mengidentifikasi permasalahan pada peternakannya sehingga dapat menemukan solusi yang sesuai (Muriithi et al., 2014). Kartu kontrol ternak dianggap kurang berpengaruh karena rata-rata kepemilikan sapi oleh peternak ralatif sedikit dan peternak masih bisa mengenali ternaknya dengan baik sehingga instrumen kartu control berada pada urutan ke-16 oleh peternak dan urutan ke-17 oleh PPL.

\section{Korelasi antara Persepsi Peternak dan Persepsi Penyuluh tentang faktor-faktor yang berpengaruh terhadap keberhasilan UPSUS SIWAB di Kutai Timur}

Uji korelasi dengan menggunakan Rank-Spearman digunakan untuk mengetahui adanya hubungan antara persepsi peternak dan persepsi penyuluh lapangan tentang 
faktor-faktor yang berpengaruh terhadap keberhasilan Upsus SIWAB di kabupaten Kutai Timur. Hubungan antara kedua persepsi tersebut dapat dilihat pada Tabel 3.

Tabel 3. Korelasi antara Persepsi peternak dan Persepsi Penyuluh Lapangan tentang faktor-faktor yang berpengaruh terhadap keberhasilan upsus siwab di kabupaten kutai timur.

\begin{tabular}{|c|c|c|c|c|}
\hline & & & Peternak & Penyuluh \\
\hline \multirow[t]{6}{*}{ Spearman's rho } & Peternak & $\begin{array}{l}\text { Correlation } \\
\text { Coefficient }\end{array}$ & 1.000 & .769 \\
\hline & & Sig.(2-tailed) & . & .000 \\
\hline & & $\mathrm{N}$ & 17 & 17 \\
\hline & penyuluh & $\begin{array}{l}\text { Correlation } \\
\text { Coefficient }\end{array}$ & .0769 & 1.000 \\
\hline & & Sig.(2-tailed) & .000 & \\
\hline & & $\mathrm{N}$ & 17 & 17 \\
\hline
\end{tabular}

Hasil analisis menunjukkan nilai koefisien korelasi Rank Spearman sebesar 0,769 sementara hasil perhitungan interpolasi nilai rho tabel untuk $\mathrm{N}=17$ sebesar 0,495 . Hal ini berarti bahwa terdapat korelasi yang kuat dan positif antara peternak dan penyuluh lapangan dalam mempersepsikan faktor-faktor yang berpengaruh terhadap keberhasilan

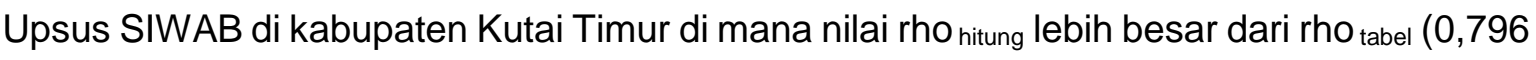
$>0,495)$. Upsus SIWAB merupakan program pemerintah dalam pembangunan pertanian, dimana kegiatan tersebut harus di tunjang oleh keberadaan peternak sebagai pelaksana pokok dalam mengelolah usaha ternak dan keberadaan penyuluh lapang sebagai penunjang dalam pelaksanaan pembangunan pertanian. Peternak dan penyuluh merupakan pelaku-pelaku dalam pembangunan. Mardikanto dan Soebiato (2015), bahwa pelaku-pelaku pembangunan terdiri dari sub-sistem pemerintah dan penggerak termasuk penyuluh (change agent) yang bertugas menginforkasikan kebijakan dan perencanaan pembangunan kepada seluruh warga masyarakat, sementara sub-sistem masyarakat yang secara positif menerima dan aktif berpartisipasi dalam pembangunan serta menerima dan memanfaatkan hasil-hasil pembangunan. Penyuluh memiliki keterampilan/keahlian yang sangat baik dalam memberikan penyuluhan atau demonstrasi yang bersifat teknis, sehingga petani mempunyai pengetahuan yang baik dalam menjalankan usahataninya.

Program Upsus SIWAB tidak hanya sekedar upaya peningkatan populasi ternak sapi, tetapi ditujukan untuk peningkatan pendapatan dan kesejahteraan keluarga peternak. Pencapaian program tersebut memerlukan dukungan dan peran pemerintah melalui penyuluh lapangan dalam memberdayakan peternak harus terus ditingkatkan. Rusdiana dan Soeharsono (2018) menyatakan bahwa pentingnya dukungan kelembagaan adalah karena kelembagaan berperan dalam menggerakkan berbagai pelaku, seperti petugas IB, penyuluh, peternak, dan pelaku usaha. Kelembagaan, seperti penyuluh dan inseminator, baik sebagai pendorong maupun pemacu dalam meningkatkan usaha sapi potong.

\section{Kesimpulan}

Persepsi peternak dan penyuluh lapangan tentang faktor-faktor yang berpengaruh terhadap keberhasilan upsus siwab di Kabupaten Kutai Timur berdasarkan rangking 
ISSN 2354-7251 (print)

instrumen dari yang paling berpengaruh adalah kondisi sapi induk, pengetahuan birahi oleh peternak, kualitas semen, pengetahuan penyuluh tentang waktu pelaksanaan IB, tingkat pendidikan PPL, ketersediaan pakan, kesadaran peternak melaksanakan IB, pendidikan peternak, Jumlah PPL dan waktu pelaksanaan IB, jarak poskeswan dengan kandang sapi induk, wilayah kerja PPL, dana operasional pemerintah, pemeriksaan kebuntingan, pola pemeliharaan sapi, identitas peternak, jaringan internet dan kartu ternak. Korelasi antara peternak dan penyuluh lapangan tentang faktor-faktor yang berpengaruh terhadap keberhasilan upsus siwab di Kutai Timur adalah positif dan kuat dengan koefisien korelasi sebesar 0,796. Tingkat kelehiran pedet hasil IB selama program Upsus SIWAB di Kabupaten Kutai Timur masih rendah sehingga perlu dilakukan penelitian lanjutan tentang strategi pencapaian target kelahiran pedet dan populasi sapi di Kutai Timur.

\section{Ucapan Terima Kasih}

Ucapan terima kasih disampaikan kepada Kementerian Riset, Teknologi dan Pendidikan Tinggi Republik Indonesia yang telah membiayai penelitian ini melalui hibah penelitian dosen pemula berdasarkan surat keputusan Nomor 7/E/KPT/2019 dan perjajian kontrak Nomor 107/KONTRAK/STIPER/VII/2019.

\section{Daftar Pustaka}

Abidin, Z. (2002). Penggemukan Sapi Potong. Jakarta: Agomedia Pustaka.

Anggraeni, A., \& Mariana, E. (2016). Evaluasi aspek teknis pemeliharaan sapi perah menuju good dairy farming practices pada peternakan sapi perah rakyat Pondok Ranggon. Jurnal Agripet, 16(2), 90-96.

Ihsan, M. N., Yekti, A. P. A., \& Susilawati, T. (2017). Pengaruh perbedaan waktu inseminasi buatan terhadap keberhasilan kebuntingan sapi Brahman Cross. Jurnal IImu-IImu Peternakan, 27(3), 17-23.

Anwas, O. M. (2013). Pengaruh pendidikan formal, pelatihan, dan intensitas pertemuan terhadap kompetensi penyuluh pertanian. Jurnal Pendidikan dan Kebudayaan, 19(1), 50-62.

Badan Pusat Statistik. (2018). Kutai Timur Dalam Angka 2017. Kutai Timur: Badan Pusat Statistik Kabupaten Kutai Timur

Baba, S., Hastang, \& Risal, M. (2015). Hambatan Pelaksanaan Teknologi IB Sapi Bali Dikabupaten Barru. Diakses tanggal 4 November 2019 dari: http://repository.unhas.ac.id/bitstream/handle/123456789/15234/Syahdar\%20Baba \%20Unhas\%202015\%20UNDIP.pdf?sequence $=1$

Baba, S., \& Risal, M. (2015). Preferensi dan tingkat pengetahuan peternak tentang teknologi IB di Kabupaten Barru. In Prosiding Seminar Nasional Peternakan. Palu. Hal (pp. 334-339).

Fatah, K., Dasrul, D., \& Abdullah, M. A. N. (2018). Perbandingan Kualitas Semen Beku Sapi Unggul dan Hubungannya dengan Tingkat Keberhasilan Inseminasi Buatan pada Sapi Aceh. Jurnal Agripet, 18(1), 10-17.

Feradis. (2010). Reproduksi Ternak. Bandung: Alfabeta. 
Haryati I. (2008). Motivasi, Kepuasan Kerja Dan Produktivitas Penyuluh Pertanian Lapangan Di Kabupaten Sukabumi. Diakses tanggal 1 November 2019 dari: https://repository.ipb.ac.id/jspui/bitstream/123456789/9861/1/2008iha_abstract.pdf

Hastuti D. (2008). Tingkat Keberhasilan Inseminasi Buatan Sapi Potong Di Tinjau Dari Angka Konsepsi Dan Service PerConception. Jurnal IImu-IImu Pertanian. 4(1): 1220

Iswoyo, I., \& Widiyaningrum, P. (2008). Performans Reproduksi Sapi Peranakan Simmental (Psm) Hasil Inseminasi Buatan di Kabupaten Sukoharjo Jawa Tengah. Jurnal IImiah IImu-IImu Peternakan, 11(3), 125-133.

Kutsiyah, F. (2012). Kelembagaan dan pembibitan Sapi Potong di Pulau Madura. Bandung: Karya Putra Darwati.

Mardikanto, T., \& P.Soebiato, (2015). Pemberdayaan Masyarakat Dalam Perspektif Kebijakan Publik. Bandung: Alfabeta.

Muriithi, K.M., Huka, S.G., \& Njati, C.I., (2014). Factors influencing growth of dairy farming business in amentia south district of mere county, Kenya. IOSR Journal of Business and Management 16(4): 21-31.

Nasution, R. (2003). Teknik Sampling. USU Digital Library. Diakses tanggal 5 Oktober 2018 dari http// library.usu.ac.id/download/fkm/fkm-rozaini.pdf.

Prasetyo, A., (15 September 2017). Kementan Sebut Capaian Upsus Siwab Masih Rendah karena Kurangnya SDM. Diakses tanggal 5 September 2018 dari http://mediaindonesia.com/read/detail/122602-kementan-sebut-capaian-upsussiwabmasih-rendah-karena-kurangnya-sdm,

Pratiwi, R. I., Suharyati, S., \& Hartono, M. (2014). Analisis Kualitas Semen Beku Sapi Simmental Menggunakan Pengencer Andromed® dengan Variasi Waktu Pre Freezing. Jurnal Ilmiah Peternakan Terpadu, 2(3).

Rangkuti, P.A. (2009). Analisis Peran Jaringan Komunikasi Petani dalam Adopsi Inovasi Traktor Tangan di Kabupaten Cianjur, Jawa Barat. Jurnal Agro Ekonomi 27(1): 4560.

Rusdiana, S. \& Soeharsono. (2018). Program SIWAB Untuk Meningkatkan Populasi sapi Potong dan Nilai Ekonomi Usaha Ternak. Forum Penelitian Agro Ekonomi 35(2):125-137

Satrio, B. W. (2018). Macam-Macam Teknik Pemeliraan Sapi Untuk Peningkatan Kualitas. Diakses tanggal 28 Agustus 2019 dari https://sains.kompas.com/read/2018 108/14/193600423/.

Sugiyono. (2015). Statistik Non Parametrik Untuk Penelitian. Bandung: Alfabeta.

Sundari \& Sionita. (2017). Pertemuan Sosialisasi Upsus Siwab. Diakses tanggal 4 November 2019 dari http://kaltim.litbang.pertanian.go.id/ind/index.php?option $=$ com_content\&view $=$ article\&id $=876 \&$ Itemid $=5$.

Toelihere, M.R. (1993). Inseminasi Buatan pada Ternak. Cetakan ke-3. Bandung: Angkasa. Van den Ban, A.W. \& H.S Hawkins. (1999). Penyuluhan Pertanian. Yogyakarta: Kanisius. 